\title{
Effect of Bulb Size and Number of Growing Axis on Seed Yield and Quality in Onion (Allium cepa L.)
}

\author{
V. R. Yalamalle*
}

Directorate of Onion and Garlic Research, Pune, Maharashtra (410 505), India

\author{
Corresponding Author \\ V. R. Yalamalle \\ e-mail: vishwanath_yal@yahoo.com
}

\author{
Article History \\ Article ID: AR1728a \\ Received in $1^{\text {st }}$ November, 2016 \\ Received in revised form $20^{\text {th }}$ November, 2016 \\ Accepted in final form $25^{\text {th }}$ November, 2016
}

\begin{abstract}
The present study was aimed to determine the effect of the number of seed bulb growing axis and the bulb size on the seed yield and seed quality in onion variety Bhima Kiran. Two independent experiments were laid out in randomized complete block design. For determining the effect of the number of growing axis medium sized bulbs (wt of $90 \pm 5 \mathrm{~g}$ ) were divided in to three groups based on number of growing axis - single, two and three centers. For determining the effect of bulb size single centered bulbs with three different sizes of bulbs- small $(60 \pm 5 \mathrm{~g}, 45 \pm 5 \mathrm{~mm}$ diameter), medium $(90 \pm 5$, diameter $55 \pm 5 \mathrm{~mm})$, and large $(120 \pm 5 \mathrm{~g}$, diameter $65 \pm 5 \mathrm{~mm})$ were used. The number of growing axis significantly enhanced the yield and yield contributing characters. The bulbs with three centers produced $63 \%$ more tillers plant $^{-1}, 35 \%$ more scapes plant ${ }^{-1}$ and $66 \%$ higher seed yield as compared to plants raised from single growing axis. The number of growing axis did not affect the seed quality characteristics. The bulb size significantly enhanced the seed yield and yield contributing characters. Large bulbs produced $58 \%$ more tillers plant ${ }^{-1}, 60 \%$ more scapes plant ${ }^{-1}$, and $48 \%$ higher seed yield as compared to small bulbs. The seed quality characteristics like 1000-seed weight, germination \%, seedling dry weight and vigour index-II were also higher in plants with large bulbs.
\end{abstract}

Keywords: Bulb size, growing axis, seed yield, quality

\section{Introduction}

Onion (Allium cepa L.) is a major bulbous crop among the cultivated vegetable crops and it has global importance. In India it is grown in 1.11 mha with the production of $15.93 \mathrm{mt}$ (FAOSTAT, 2013). The productivity of onion in India is $14.35 \mathrm{t}$ $\mathrm{ha}^{-1}$, which is much lower than the productivity of Netherlands, USA and China. One of the major reason for lower productivity of onion in Indiais the limited availability of quality seed and poor seed replacement rate (Tomar, 2011).

Onion seed production is a biannual process. The seed bulb forms the planting material during the second season for seed production; its quality plays an important role in getting the quality seeds (Mosleh UD-Deen, 2008). The effect of bulb size on seed yield is extensively studied and has been reported that the bulb size is linearly related to the seed yield and quality (Mishra, 1986; Kokhar, 2008; Ashrafuzzaman et al., 2009; Morozowska and Holubowicz, 2009). Increase in the bulb size is also associated with the increase in the number of growing axis. None of the previous studies have has mentioned the number of growing axis in their experiment material. Onion bulb is a modified shoot and has many adventitious shoot at the base which sprouts and differentiates into scape during subsequent growth. Multi-centered bulbs are formed due to axillary branching in onion. Single centeredness in onion depends on cultivars and have low heritability (Shock et al., 2005), but is also depends on the environment as well as management factors. Clinton et al. (2007) has reported that the short duration water stress increases the percentage of multi-centered bubs. To our knowledge, no work on the effect of different bulb growing axis on onion seed yield and quality has not been reported.

Since the effect of planting different centered bulbs and different size of bulb keeping the number of growing centered constant has not been reported. The present study was initiated. Specifically, the study aims to determine the effect of using multi centered bulbs and different size of bulb on seed yield and quality attributes in onion seed crop.

\section{Materials and Methods}

\subsection{Description of experiment site}

The present experiment was conducted in research fields of ICAR-Directorate of Onion and Garlic Research, Pune, India during rabi/winter 2013-14. Rajgurunagar is located in the Western Maharashtra Plain zone (Basu et al., 1996) the average variation in temperature and $\mathrm{RH}$ during the experimental period was $15-30^{\circ} \mathrm{C}$ and $40-69 \%$ respectively. 
The experiment was laid out in randomized complete block design with four replications. The randomization was done using design resource server (Parsad et.al, 2013). The seed bulbs were planted in ridges and furrows method at a spacing of $60 \times 20 \mathrm{~cm}^{2}$ on drip. The bulbs were planted on $22^{\text {nd }}$ November, 2013. The plots were fertilized with 150:50:50 (N: $\mathrm{P}: \mathrm{K})$ and $10 \mathrm{t} \mathrm{FYM} \mathrm{ha}{ }^{-1}$, with full basal dose of $\mathrm{P}$ and $\mathrm{K}$. Half of the nitrogen was applied as basal dose and remaining dose was applied in two equal dose at 25 and 50 days after planting. The plots were irrigated regularly throughout the crop cycle to avoid water stress. The weeds were managed by spraying $0.2 \%$ pre-emergent herbicide Oxyflurofen 23.5 EC (Goal ${ }^{\circledR}$ ) and weeds at later stage were controlled by hand weeding.

\subsection{The planting material}

\subsubsection{Experiment one}

For determining the effect of the number of growing axis medium sized bulbs (wt of $90 \pm 5 \mathrm{~g}$ and diameter $55 \pm 5 \mathrm{~mm}$ ) were cut $1 / 3^{\text {rd }}$ from the top to know the number of growing axis and were divided in to three groups based on number of growing axis- single, two and three centered (Figure 1) and were used as planting material.
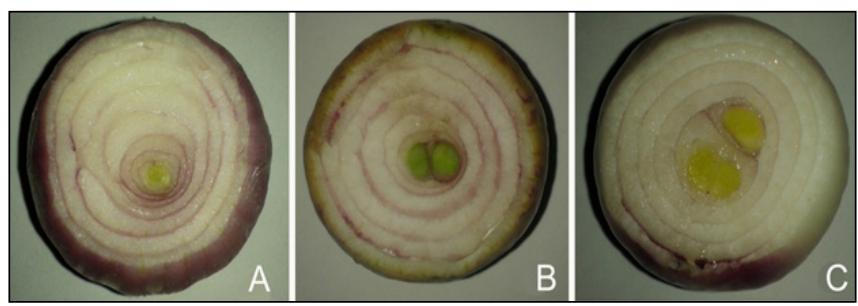

Figure 1: Onion seed bulbs with three different growing axis: (A) seed bulbs with single growing axis, (B) seed bulbs with two growing axis, $(C)$ seed bulbs with three growing axis

\subsubsection{Experiment two}

For determining the effect of bulb size single centered bulbs with three different size of bulbs small $(60 \pm 5 \mathrm{~g}, 45 \pm 5 \mathrm{~mm}$ diameter), medium ( $90 \pm 5 \mathrm{~g}$, diameter $55 \pm 5 \mathrm{~mm}$ ), large (120 \pm 5 $\mathrm{g}$ and diameter $65 \pm 5 \mathrm{~mm}$ ) were used as planting material.

\subsection{Measurement and analysis}

The data on number of tillers plant ${ }^{-1}$ and number of scapes plant ${ }^{-1}$ was recorded from 10 randomly selected plants after40 days after planting and were averaged. The data on, scape diameter and scape length were recorded at the anthesis. The umbels were considered to be ready for harvest, when about 20-30\% of the seeds in the umbel turned black. The harvested umbels were sundried, threshed manually and the seed yield ten $^{-1}$ plants and 1000 seed weight was recorded and averaged.

2.3.1. Spread of scape emergenceand days to first scape emergence

The scape emergence was recorded daily. The appearance of unopened scape was considered as scape emergence and the days to first scape emergence were recorded. Spread of scape was calculated by formula:
Spread of flowering $=\{(D F F-D L F) / N F\}$

(DPF-days to appearance of first flower, DLF-days to appearance of last flower, NF-number of flowers).

\subsubsection{Seed germination}

50 seeds in three replication were placed on top of moist blotter papers in the $12.5 \mathrm{~cm}$ petri dishes at $25^{\circ} \mathrm{C} \pm 1$ in germinator. Water requirements was checked daily and topped-up according to necessity. The first count and final count was taken on $6^{\text {th }}$ and $12^{\text {th }}$ day. The germination $\%$ was calculated on normal seedling as per ISTA (2007) protocol.

\subsubsection{Seedling vigour}

Ten normal seedlings were randomly selected at final count during germination test and dried at $60^{\circ} \mathrm{C}$ till constant weight. The seedling vigour index was calculated by modified vigour index of Abdul Baki Anderson (1973)

Seedling vigour index-I=Germination \%xaverage seedling length of 10 seedlings in $\mathrm{mm}$. Seedling vigour index- $\mathrm{II}=$ Germination $\% \times$ average weight of 10 seedlings in $\mathrm{mg}$.

\subsection{Data analysis}

Statistical analysis was performed by using statistical analysis system (SAS) version 9.3. The data collected were subjected to analysis of variance and means were separated by least significant difference test (at $p=0.05$ ). Duncan's multiple range test was used to compare the difference among the treatment means. Percentages were arcsine transformed prior to analysis.

\section{Results and Discussion}

3.1. Effect of no. of growing axis on vegetative and reproductive characters

The number of tillers significantly increased with the number of growing axis. Highest number of tillers was found in bulbs with three growing axis, which was $63 \%$ more than the bulbs with single growing axis (Table 1). The increase in number of tillers could be attributed to the more number of adventative

Table 1: Effect of number of growing axis on vegetative and reproductive characters

\begin{tabular}{lllcccc}
\hline Treatment & NTP & NSP & SF & DFF & SL & UD \\
\hline $\mathrm{T}_{1}$ & $3.97_{\mathrm{b}}$ & $3.85_{\mathrm{b}}$ & $7.37_{\mathrm{b}}$ & 50.17 & 53.79 & 57.13 \\
$\mathrm{~T}_{2}$ & $5.70_{\mathrm{a}}$ & $5.37_{\mathrm{a}}$ & $12.02_{\mathrm{a}}$ & 47.50 & 54.68 & 60.15 \\
$\mathrm{~T}_{3}$ & $6.47_{\mathrm{a}}$ & $5.20_{\mathrm{a}}$ & $11.77_{\mathrm{a}}$ & 45.07 & 52.59 & 58.02 \\
$\mathrm{CD}(p=0.05)$ & 1.62 & 0.93 & 3.29 & $\mathrm{NS}$ & $\mathrm{NS}$ & $\mathrm{NS}$ \\
$\mathrm{SEm} \pm$ & 0.47 & 0.27 & 0.95 & 1.65 & 2.02 & 1.41 \\
\hline
\end{tabular}

NTP: No. of tillers ${ }^{-1}$ plant; NSP: No. of scapes $^{-1}$ plant; SF: Spread of flowering (days); DFF: Days to first flowering (days); SL: Scape length (cm); UD: Umbel diameter (mm); Means with at least one letter common are not statistically significant using Duncan's Multiple Range Test for $p=0.05$ 
buds which also result in the increase of number of scape. Bulbs with three growing axis produced $35 \%$ more scapes in comparison with the bulbs with single growing axis. Onion bulb is modified shoot more the number of adventative buds more is the number of tillers and scapes. Wurr et al., 2001, reported that increase in number of buds ${ }^{-1}$ tuber was positively related to the number of sprouts $^{-1}$ plant and tuber size in potato. The spread of scape emergence were lowest in bulbs with single growing axis. The days to first scape emergence, scape length, umbel diameter did not differ significantly between treatments.

\subsubsection{Effect of number of growing axis on seed yield and seed quality attributes}

The seed yield plant ${ }^{-1}$ significantly differed with the treatments. Plants with three growing axis produced highest seed yield plant ${ }^{-1}$ which was $66 \%$ more than the bulbs with single growing axis (Table 2). The increase in the yield could be attributed to the more number of scapes plant ${ }^{-1}$. Seed quality parameters like 1000 seed weight, germination \%, seedling length, seedling dry weight, Vigour index-I were non-significant, except for vigour index-II which was highest in treatment $\mathrm{T}_{2}$ (two centered bulbs).

\subsection{Effect of bulb size on vegetative and reproductive} characters

The numbers of tillers significantly increased with the increase in bulb size, highest number of tillers were found in large bulbs, which was $58 \%$ more than small bulbs (Table 3 ), this could be attributed to more stored carbohydrates reserves in

Table 2: Effect of number of growing axis on seed yield and seed quality

\begin{tabular}{lccccccc}
\hline Treatment & $\begin{array}{c}\text { Seed yield } \\
\left(\mathrm{g}^{-1} 10 \text { plants) }\right.\end{array}$ & $\begin{array}{c}1000 \text { seed } \\
\text { wt }(\mathrm{g})\end{array}$ & $\begin{array}{c}\text { Germination } \\
\%^{*}\end{array}$ & $\begin{array}{c}\text { Seedling length } \\
(\mathrm{mm})\end{array}$ & $\begin{array}{c}\text { Seedling dry } \\
\text { weight }(\mathrm{mg})\end{array}$ & $\begin{array}{c}\text { Vigour } \\
\text { index-I }\end{array}$ & $\begin{array}{c}\text { Vigour } \\
\text { index-II }\end{array}$ \\
\hline $\mathrm{T}_{1}$ & $78.80_{\mathrm{b}}$ & 3.20 & $88(69.78)$ & 60.99 & 1.60 & $5365.15_{\mathrm{b}}$ & 141.67 \\
$\mathrm{~T}_{2}$ & $91.05_{\mathrm{b}}$ & 3.32 & $91(72.69)$ & 66.11 & 1.79 & $6017.03_{\mathrm{a}}$ & 163.26 \\
$\mathrm{~T}_{3}$ & $131.50_{\mathrm{a}}$ & 3.14 & $88(69.63)$ & 61.40 & 1.61 & $5377.46_{\mathrm{b}}$ & 141.22 \\
$\mathrm{CD}(p=0.05)$ & 36.58 & $\mathrm{NS}$ & $\mathrm{NS}$ & $\mathrm{NS}$ & $\mathrm{NS}$ & 517.7 & $\mathrm{NS}$ \\
$\mathrm{SEm} \pm$ & 10.57 & 0.08 & 1.14 & 1.40 & 0.07 & 149.62 & 7.25 \\
\hline
\end{tabular}

Means with at least one letter common are not statistically significant using Duncan's multiple range test for $p=0.05$; Values in parenthesis are arc sine transformed values

Table 3: Effect of bulb size on vegetative and reproductive characters

\begin{tabular}{lllllll}
\hline Treatment & NTP & NSP & \multicolumn{1}{c}{ SF } & DFF & SL & UD \\
\hline $\mathrm{T}_{1}$ & $4.20_{\mathrm{a}}$ & $4.00_{\mathrm{a}}$ & $9.29_{\mathrm{a}}$ & 49.01 & 56.80 & 59.41 \\
$\mathrm{~T}_{2}$ & $3.47_{\mathrm{ab}}$ & $3.17_{\mathrm{ab}}$ & $5.78_{\mathrm{b}}$ & 51.36 & 55.61 & 57.74 \\
$\mathrm{~T}_{3}$ & $2.65_{\mathrm{b}}$ & $2.50_{\mathrm{b}}$ & $4.65_{\mathrm{b}}$ & 50.24 & 52.18 & 56.46 \\
$\mathrm{CD}(p=0.05)$ & 1.11 & 1.13 & 3.50 & $\mathrm{NS}$ & $\mathrm{NS}$ & $\mathrm{NS}$ \\
$\mathrm{SEm} \pm$ & 0.32 & 0.33 & 1.01 & 1.25 & 3.60 & 1.94 \\
\hline
\end{tabular}

Means with at least one letter common are not statistically significant using Duncan's multiple range test for $p=0.05$ large bulbs and subsequent availability to the growing plants (Khokhar, K.M., 2008). Large bulbs produced $60 \%$ more scapes in comparison with small bulbs. More number of tillers in turn produced more number of scapes and the result were in conformity with the previous findings of Mishra, 1986; Kokhar 2008; Ashrafuzzaman et al., 2009; Morozowska and Holubowicz, 2009.

3.2.1. Effect of bulb size on seed yield and seed quality attributes

The seed yield plant $^{-1}$ significantly increased with the bulb size. Highest seed yield was obtained in bulb weight $120+5$ g which was $48 \%$ more than the smaller bulbs (Table 4$)$. The

\begin{tabular}{lccccccc}
\hline \multicolumn{2}{l}{ Table 4: Effect of bulb size on seed yield and seed quality } \\
\hline Treatment & $\begin{array}{c}\text { Seed yield } \\
\left(\mathrm{g}^{-1} 10 \text { plants }\right)\end{array}$ & $\begin{array}{c}1000 \text { seed } \\
\text { wt }(\mathrm{g})\end{array}$ & $\begin{array}{c}\text { Germination } \\
\%^{*}\end{array}$ & $\begin{array}{c}\text { Seedling length } \\
(\mathrm{mm})\end{array}$ & $\begin{array}{c}\text { Seedling dry } \\
\text { weight }(\mathrm{mg})\end{array}$ & $\begin{array}{c}\text { Vigour } \\
\text { index-I }\end{array}$ & $\begin{array}{c}\text { Vigour } \\
\text { index-II }\end{array}$ \\
\hline $\mathrm{T}_{1}$ & $73.55_{\mathrm{a}}$ & $3.31_{\mathrm{a}}$ & $88.75(72.92)_{\mathrm{a}}$ & 59.45 & $1.77 \mathrm{a}$ & 5842.30 & $161.52 \mathrm{a}$ \\
$\mathrm{T}_{2}$ & $66.46_{\mathrm{a}}$ & $3.23_{\mathrm{ab}}$ & $91.50(73.17)_{\mathrm{a}}$ & 66.16 & $1.65_{\mathrm{b}}$ & 6054.97 & $151.24 \mathrm{ab}$ \\
$\mathrm{T}_{3}$ & $49.43_{\mathrm{b}}$ & $3.14_{\mathrm{b}}$ & $88.75(69.96)_{\mathrm{b}}$ & 63.97 & $1.63_{\mathrm{c}}$ & 5245.64 & $143.53 \mathrm{~b}$ \\
$\mathrm{CD}(p=0.05)$ & 16.40 & 0.13 & 2.46 & $\mathrm{NS}$ & 0.11 & $\mathrm{NS}$ & 12.10 \\
$\mathrm{SEm} \pm$ & 4.74 & 0.04 & 0.71 & 0.19 & 0.03 & 199.64 & 3.50 \\
\hline
\end{tabular}

Means with atleast one letter common are not statistically significant using duncan's multiple range test for $p=0.05$; $*$ values in parenthesis are arc sine transformed values 
increased seed yield could be due to more number of tillers, scapes and improved supply of food materials from the source at the initial stage and the result were in conformity with the previous findings of Mishra, 1986; Kokhar, 2008; Ashrafuzzaman et al., 2009; Morozowska and Holubowicz, 2009.

The 1000 seed weight increased with the increase in bulb size previous studies by Ashrafuzzaman et al., 2009 also reported that 1000 seed weight increased linearly with the increase in bulb size. Germination \% did not differ with the bulb size; highest seedling weight was obtained in bulb size $(90+5 \mathrm{~g})$. The seedling length, VI-II were not affected by the bulb size the result are in conformity with the findings of finds of Morozowska and Holubowicz, 2009.

\section{Conclusion}

For maximizing the yields the onion seed producers may use multi-centered seed bulbs as planting material in those variety where single centeredness is not the desired character. The onion bulb size of 90-120 g may be used to get higher seed yield and good seed quality.

\section{Acknowledgement}

The present study was funded by institute grants of Indian Council for Agricultural Research-Directorate of Onion and Garlic Research, Pune, India.

\section{References}

Ashrafuzzaman, M., Millat, M.N., Ismail, M.R., Uddin, M.K., Shahidullah, S.M., Meon, S., 2009. Paclobutrazol and bulb size effect on onion seed production. International Journal of Agriculture and Biology 11, 245-250.

Basu, D.N., Guha, G.S., Kashyap, S.P., 1996. Agro-climatic
Regional Planning in India concept and applications. In: Kashyap, S.P. (Ed.), Agro-climatic Regional Planning in India. Concept Publishing Company, India, 280.

FAO, 2013. www.faostat.fao.org. Accessed in October 2013. Gupta, R.P., Sharma, H.P., 2011. Onion and garlic seed requirement, constraints and future strategy. In: National Symposium on Alliums 2011: Current Scenario and Emerging Trends, Pune, India, 56-63.

ISTA., 2007. International rules for seed testing( $1^{\text {st }}$ edition), International seed testing association, Bassersdorf, Switzerland.

Khokhar, K.M., 2008. Effect of set-size and planting time on the incidence of bolting, bulbing and seed yield in two onion cultivars. The Journal of Horticultural Science and Biotechnology 83, 481-487.

Tomar, B.S., 2011. Quality seed production technology of onion crops in India.http://www.krishisewa.com/cms/ articles/seed-production/203-onion-sp.html.

Mishra, H.P., 1986. Effect of time of planting and size of mother bulbs on onion seed production. Indian Journal of Horticulture 43, 140-143.

Morozowska, M., Hołubowicz, R., 2009. Effect of bulb size on selected morphological characters of seed stalks, seed yield and quality of onion (Allium cepa L.). Folia Horticulture 21, 27-38.

Parsad, R., Gupta, V.K., Dhandapani, 2013. Indian Agricultural Statistics Research Institute (ICAR), New Delhi 110012, India. Available from http://www.iasri.res.in/design.

Wurr, D.C.E., Fellows, J.R., Akehurst, J.M., Hambidge, A.J., Lynn, James, R., 2001. The effect of cultural and environmental factors on potato seed tuber morphology and subsequent sprout and stem development. Journal of Agricultural Science 13(1), 55-63. 